\title{
The Stability Evaluation of Roadway Surrounding Rock in Qingfeng Coal Mine
}

\author{
Pai-Ke WEN ${ }^{1,2, a}$, Yu-Jun ZUO ${ }^{1,2,3, b_{*}}$, Xiao-Yan PU,cc, Yue-Qin QIU ${ }^{1,2,3, d}$, \\ Bo TANG ${ }^{1,2, \mathrm{e}}$
}

${ }^{1}$ Mining College, Guizhou University, Guiyang, Guizhou, 550025, China

${ }^{2}$ Guizhou Key Laboratory of Comprehensive Utilization of Non-metallic Mineral Resources, Guizhou University, Guiyang, Guizhou, 550025, China

${ }^{3}$ Guizhou Engineering Lab of Mineral Resources, Guizhou University, Guiyang, Guizhou, 550025, China

${ }^{4}$ Foreign Languages College, Guizhou University, Guiyang, Guizhou, 550025, China

a838984059@qq.com, b*zuo.yujun@yahoo.com.cn, '360715438@qq.com, d631958848@qq.com, 812655376@qq.com

${ }^{*}$ Corresponding author

Keywords: Roadway Surrounding Rock, Coal Mine, Protodyakonov's Theory, Phase ${ }^{2}$, Numerical Simulation.

\begin{abstract}
In order to have a better understanding on the stability of roadway surrounding rock in QingFeng coal mine. Protodyakonov's theory is used to evaluate its stability theoretically, then a numerical simulation is conducted to analyze the stability of roadway surrounding rock in natural state by using the phase ${ }^{2}$ finite element software. The stress distribution law and strain distributing disciplinarian are gained, the total displacement and the strength factor of the surrounding rock are also obtained by numerical simulation. The results show the deformation of roadway surrounding rock is small and the two joints around roadway have great influence on the stability of roadway surrounding rock. The comprehensive application of the two methods can provide an important reference for stability evaluation of other roadway surrounding rocks.
\end{abstract}

\section{Introduction}

With the mine exploiting more and more deeply, the ground stress also becomes increasingly large, the roadway surrounding rock pressure will show accumulation phenomenon, often give rise to collapse and roof fall accident, especially when the roadway meets the fault, fracture and so on in the excavation, this makes the roadway maintenance more complicated. Therefore, it is very important to study the stress distribution of roadway and judge the stability of the roadway surrounding rock during roadway excavation for the rock support design and construction of the tunnel, which directly affects the mining safety and economy[1-2].

For underground mining, the stability of roadway surrounding rock, rock movement law and impact of support and mining stope have always been the important content which is concerned by mine technical personnel. At the same time, it is also an important aspect, difficult and hot point of the scientific and technological research. Ensuring the roadway stability is the precondition for safe and stable production of the mine. Besides, the stability of roadway surrounding rock has always been an important research content of the geotechnical engineering, the evaluation results of surrounding rock stability determine the success or the failure of the underground project. Therefore, understanding the stability of the surrounding rock is significant to the security of the mine and guidance for the mine production reality[3-5].

At present, many experts have done a lot of research on the evaluation of surrounding rock stability, the analysis methods mainly include analytical method, numerical analysis method, block limiting equilibrium method, engineering geological method, the uncertain method etc[6]. However, study on the stability evaluation of roadway surrounding rock by using more than two methods at 
the same time is comparatively little. In this paper, we take the QingFeng coal mine as example. Firstly, make stability evaluation with Protodyakonov's theory. Then, establish a numerical model with Phase 2 software, analyze the surrounding rock pressure and stress distribution in natural state. The results can provide an important reference for subsequent support design.

\section{A Brief Introduction of Geological Situation in Qingfeng Coal Mine}

The geological structure in QingFeng coal mine is relatively simple. The strata in mining areas mainly include triassic and permian. The coal-bearing formation is the upper permian. There is only one coal seam in this region. The thickness of coal seam is $0.55 \sim 3.5 \mathrm{~m}$, the average thickness is about $2 \mathrm{~m}$. The structure of coal seam is simple, there are not gangues. Above the coal seam, there is a sand-shale, its thickness is 8 metre. Below the coal seam, there is a sandstone, its thickness is very large.

\section{The Evaluation of Stability for Roadway Surrounding Rock by Protodyakonov's Theory}

Protodyakonov's theory was put forward by Russian scholars in 1926. They thought that all the surrounding rocks are divided by cracks and joints in different degrees. Hower, the surrounding rock is different from general bulk solids, and there exist different magnitudes of cohesion. In order to reflect the destruction-resisting ability of surrounding rock under composite action of several deformation mode, the concept of consistent coefficient is put forward[7-9].

Surrounding rock classification by Protodyakonov's theory is a typical single-index rock classification, which can be expressed as follows:

$$
\mathrm{f}=\mathrm{Rc} / 10
$$

Where, Rc is the uniaxial compressive strength of rock, MPa. According to Protodyakonov's classification, when the value of $\mathrm{f}$ is less than 4 , the rock belongs to soft rock, when $\mathrm{f}$ is within 4 7, the rock belongs to moderate hard rock, when $\mathrm{f}$ is more than 7 , the rock belongs to hard rock. As index of the method is single, it can directly reflect the strength characteristics of the rock and is easy and convenient, it has been widely used in our country's mine in the Period of the 1980's and a variety of underground projects, and has remained widely used in shallow buried underground engineering. We obtain the firm coefficient is 6.3 by caculation. According to mine rock classification, the roadway surrounding rock in the mine is good in quality on the whole.

\section{The Evaluation of Stability for Roadway Surrounding Rock By Phase2 Software}

\section{Brief Introduction of Phase2 Software}

Phase2 is a powerful 2D elasto-plastic finite element stress analysis program for underground or surface excavations in rock or soil. It can be used for a wide range of engineering projects and includes support design, finite element slope stability and groundwater seepage analysis. Complex, multi-stage models can be easily created and quickly analyzed, for example: tunnels in weak or jointed rock, underground powerhouse caverns, open pit mines and slopes, embankments, MSE stabilized earth structures, and much more. Progressive failure, support interaction and a variety of other problems can be addressed[10-11].

Phase2 offers a wide range of support modeling options. Liner elements can be applied in the modeling of shotcrete, concrete, steel set systems, retaining walls, piles, multi-layer composite liners, geotextiles and more. New liner design tools include support capacity plots which allow you to determine the safety factor of reinforced liners. Bolt types include end anchored, fully bonded, cable bolts, split sets and grouted tiebacks.Phase2 includes steady state, finite element groundwater seepage analysis built right into the program. There is no need to use a separate groundwater program. Pore pressure is determined as well as flow and gradient, based on user defined hydraulic boundary conditions and material conductivity. Pore pressure results are automatically incorporated 
into the stress analysis[12].

\section{Numerical Model and Scheme}

When the rock mechanics parameters that the numerical simulation needs are closer to the actual situation, the simulating results are better. As the simulating results can not be completely consistent with the engineering pracitise in actual modeling process, we should make a further simplification for engineering practise. The rock mechanics of the coal and strata are based on the test results of the core. The stress-strain of strata and material vary from elasticity to plasticity, the ground stress field is automatically generated by gravity. The mechanical properties of rock are shown in table1. The caculation model's length and height are respectively $36 \mathrm{~m}$ and $35 \mathrm{~m}$, there are $100 \mathrm{~m}$ overlying strata weight that insteaded by the uniform load on top of the model. The model is divided into 2308 unit body grids and 1251 nodes.

The boundary conditons of the model are as follows: lateral faces and bottom surface are the displacement boundaries, the lateral faces limit horizontal displacement and the bottom surface limits vertical displacement, the upper boundary is free surface. The model size and boundary conditions are shown in figure.1.

Tab. 1 Mechanical Properties of Rock

\begin{tabular}{|c|c|c|c|c|c|c|}
\hline name & $\begin{array}{c}\text { Young } \\
\text { modulus } \\
{[\mathrm{MPa}]}\end{array}$ & $\begin{array}{c}\text { Poisson } \\
\text { ration }\end{array}$ & $\begin{array}{c}\text { Cohesio } \\
n \\
{[\mathrm{MPa}]}\end{array}$ & $\begin{array}{c}\text { Friction } \\
\text { angle } \\
{\left[{ }^{0}\right]}\end{array}$ & $\begin{array}{c}\text { Tensile } \\
\text { strength }[\mathrm{MPa}]\end{array}$ & $\begin{array}{c}\text { Bulk density } \\
{\left[\mathrm{MN} \cdot \mathrm{m}^{-3}\right]}\end{array}$ \\
\hline $\begin{array}{c}\text { Weak } \\
\text { limestone }\end{array}$ & 5100 & 0.20 & 20.5 & 27 & 40.7 & 0.024 \\
\hline Sand-shale & 2100 & 0.22 & 11.3 & 24 & 63 & 0.021 \\
\hline Coal seam & 1020 & 0.27 & 6.50 & 26 & 8.0 & 0.015 \\
\hline Sandstone & 6850 & 0.18 & 27.2 & 27 & 13.6 & 0.026 \\
\hline Joint & 500 & 0.20 & 0.12 & 25 & 0.1 & 0.011 \\
\hline & & (2) & 1 & 11 & 24 & \\
\hline
\end{tabular}

Fig. 1 Numerical Model

Mohr-Coulomb yield criterion is used for simulation calculation, namely:

$$
\begin{aligned}
& \mathrm{f}_{\mathrm{s}}=\sigma_{1}-\sigma_{3} \frac{1+\sin \varphi}{1-\sin \varphi}-2 \mathrm{c} \sqrt{\frac{1+\sin \varphi}{1-\sin \varphi}} \\
& \mathrm{f}_{\mathrm{s}}=\sigma_{1}-\sigma_{\mathrm{t}}
\end{aligned}
$$

During the above formulae, $\sigma_{1}$ represents maximum stress, $\sigma_{3}$ represents minimum stress, $\mathrm{c}$ represents bond force, $\varphi$ represents internal friction angle, $\sigma_{t}$ represents tensile strength. 


\section{Numerical Results}

Fig.2 reflects the distribution of stress. From the fig.2(a), we can know sigmal is mainly concentrated on the roadway roof and roadway's sides. The maximum Sigma 1 is at the sharp corner at the lower left and its value is about $45 \mathrm{MPa}$. However, the values of sigmal are very small near the region of the two joints, which indicate the existing of the two joints play an action of pressure relief to some degree. From the fig.2(b), we can know sigma3 mainly appears at the sharp corner of the intersections between roadway's sides and roadway floor, and its maximum value is about $13 \mathrm{MPa}$. Besides, the distribution of sigma3 around surrounding rock is relatively uniform, the values are small and vary between $1 \sim 3 \mathrm{MPa}$. The deeper region of surrounding rock varys between about $4 \sim 10$.

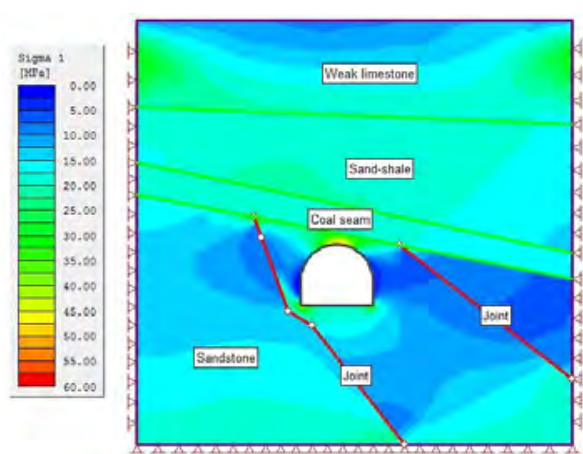

(a) The Distribution of Sigma 1

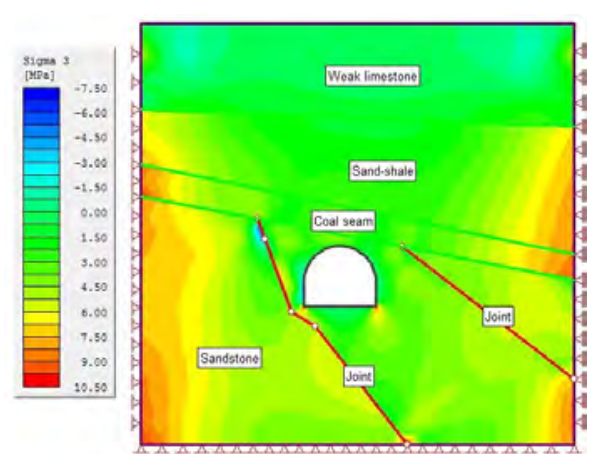

(b) The Distribution of Sigma3

Fig. 2 The Distribution of Stress

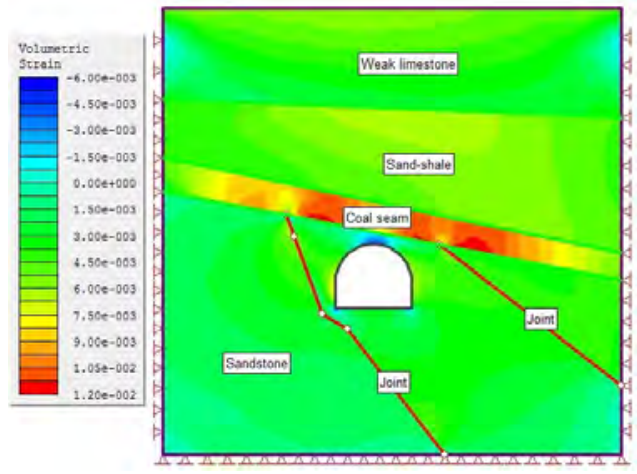

(a) The Distribution of Volumetric Strain

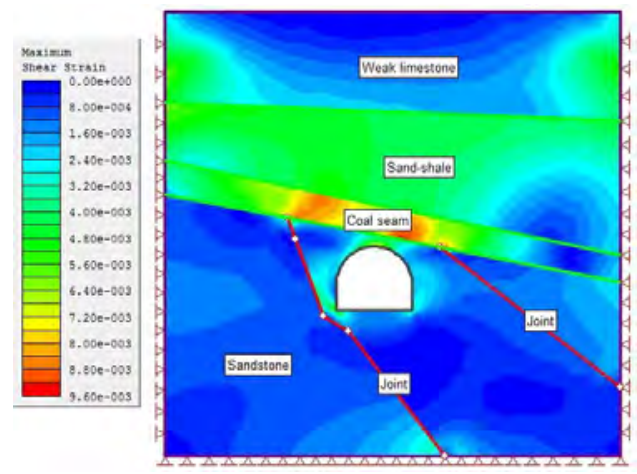

(b) The Distribution of Maxium Shear Strain

Fig. 3 The Distribution of Strain

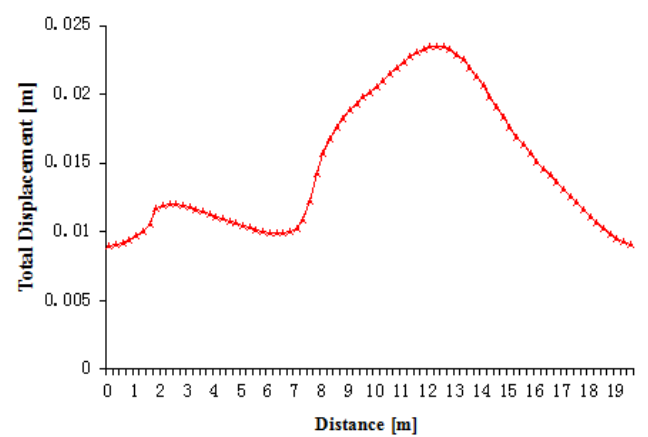

Fig. 4 The Displacement Graph of Roadway Surrounding Rock

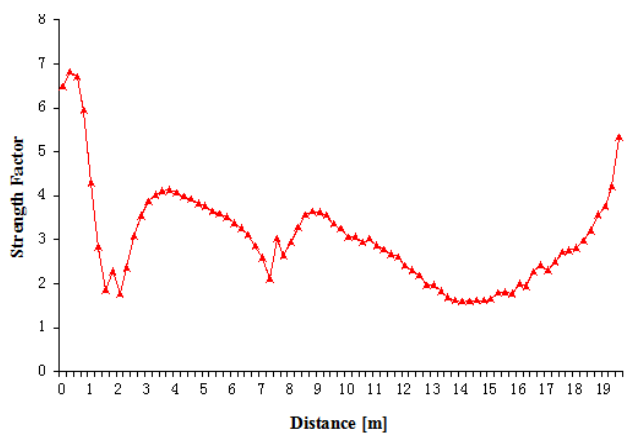

Fig. 5 The Strength Factor Graph of Roadway Surrounding Rock

As is shown in the fig.2(a), the distribution of volumetric strain are mainly concentrated on the region which is located in the coal seam of upper-right of roadway, and the values vary between $3 \times 10-3 \sim 6 \times 10-3$. Besides, the region between the two joints also has large distribution, and the 
values vary between $1 \times 10-3 \sim 3 \times 10-3$. Obviously, the existing two joints have a great influence on the distribution of volumetric strain. Fig.2(b) reflects the distribution of maxium shear strain, which are mainly concentrated on the surrounding rock and the coal seam which are around the two joints. The maximum value is about $7.0 \times 10-3$ and is located in the coal seam.

As is shown in the Fig.4, the total displacement of the whole surrounding rock is small, the maximal displacement appears when the distance is $12.5 \mathrm{~m}$, and its value is $0.0235 \mathrm{~m}$. From the distribution of total displacement, we can know the roadway is in the state of stability. The relationship between strenth factor and distance is shown in Fig.5, the maximal strength factor appears when the distance is $0.5 \mathrm{~m}$, and its value is about 7 .

\section{Conclusions}

(1)The stability of rock around roadway is evaluated theoretically by Protodyakonov's theory. The results show that the roadway surrounding rock has good stability.

(2)A finite element analysis and simlation is conducted to simulate the stability of rock around roadway by using the phase ${ }^{2}$ numerical software. The stress distribution law and strain distributing disciplinarian are gained, the total displacement and the strength factor of the surrounding rock are also obtained. Simulation results show the deformation of roadway surrounding rock is small and the two joints around roadway have great influence on the stability of roadway surrounding rock.

(3)The Protodyakonov's theory and phase ${ }^{2}$ simulation results both show that the roadway surrounding rock is in the state of stability. The comprehensive application of the two methods can provide an important reference for stability evaluation of other roadway surrounding rocks.

\section{Acknowledgements}

The present work is supported by the Plan Key Projects Supported by National Science and Technology of China (Grant No.2012BAB08B06), Guizhou Province Key Project of Natural Science of China (Grant 2010003), Guizhou Province Governor Outstanding Science and Technology Education Fund Project (Grant No. (2011) 36), High Level Talents in Guizhou Province of China Research Conditions Help Fund Project (Grant No. TZJF-2010-044), and the Innovation Fund of Mining College of Guizhou University (Grant No. 2012008). These supports are gratefully acknowledged. The authors are grateful to the reviewers for discerning comments on this paper.

\section{References}

[1]MENG Qing-bin, HAN Li-jun, QIAO Wei-guo, et al. Numerical simulation of cross-section shape optimization design of deep soft rock roadway under high stress[J]. Journal of Mining \& Safety Engineering, 2012, 29(5): 650-656.

[2]GUO Jian-wei, LIU Quan-sheng, YANG Zhan-biao, et al. Support technology to deep large-scale soft surrounding rock of roadway in pingdingshan coal mine[J]. Chinese Journal of Rock Mechanics and Engineering, 2012, 31(s2): 3904-3910.

[3]LI Gui-chen, ZHANG Nong, WANG Cheng, et al. Optimizing the section shape of roadways in high stress ground by numerical simulation[J]. Journal of China University of Mining \& Technology, 2010, 39(5):652-658.

[4]ZHANG Teng, HU Bin, WANG Wei, et al. Analysis of soil slope stability based on phase2 strength reduction method[J]. Yellow River, 2014, 36(3): 135-137.

[5]FAN Cai-bing, LI Zhan-ke, WANG Xue-ming. Numerical simulation on the final sloping angle of the open-pit mine[J]. Metal Mine, 2012, 41(7):59-63.

[6]MIAO Yu-song, ZHANG Yi-ping, ZUO Yu-jun, et al. Stability analysis of the surrounding rock 
of a tunnel in Aipu iron mine[J]. Metal Mine, 2012, 41(2):57-59.

[7]YANG Biao, LUO Zhou-quan, LIU Xiao-ming, et al. Dangerous degree estimation of complicated goaf group with FEM simulation[J]. Mineral Engineering Research, 2010, 25(1):4-7.

[8]WEI Tao, SHAO Xiao-mei, ZHANG Jian. Latest research and application of chemical grouting technology in water conservancy industry[J]. Journal of Yangtze River Scientific Research Institute, 2014, 31(2):73-76.

[9]HE Man-chao, GUO Hong-yun, CHEN Xin, et al. Numerical simulation analysis of largedeformation of deep soft rock engineering based on solar decomposition theorem[J].Chinese Journal of Rock Mechanics and Engineering, 2010, 29(s2):4051-4055.

[10]YE Shan, OUYANG Zhi-hua, GONG Jian. Comprehensive evaluation of stability in Pu-De mine while mining residual ore[J]. Metal Mine, 2010, 39(9): 155-158.

[11]MAO Xin-sheng. Evaluation of surrounding rock quality and determination of its strength parameters by the method of RMR and fuzzy pattern recognition[J].Northwest Hydropower, 2008(6): 3-6.

[12]LUO Zhou-quan, LIU Xiao-ming, WU Ya-bin, et al. Study on cavity stability numerical simulation based on coupling of surpac and phase ${ }^{2}[\mathrm{~J}]$. Journal of Liaoning Technical University(Nature Science), 2008, 27(4): 485-488. 